Journal of Mathematics and Statistics 4 (4): 231-235, 2008

ISSN 1549-3644

(C) 2008 Science Publications

\title{
Almost Graded Prime Ideals
}

\author{
${ }^{1}$ Ameer Jaber, ${ }^{1}$ Malik Bataineh and ${ }^{2}$ Hani Khashan \\ ${ }^{1}$ Department of Mathematics, The Hashemite University, Zarqa, 13115, Jordan \\ ${ }^{2}$ Department of Mathematics, Al-Albayt University, Mafraq, Jordan
}

\begin{abstract}
Problem Statement: Graded commutative ring with unity over an abelian group were introduced by many authors such as T. Y. Lam and C. T. C. Wall, and almost prime ideals over commutative rings with unity were introduced by S.M. Batwadeker and P.K. Sharma, and this forced us to try to extend the theory of almost and n-almost prime ideals to the graded case. Approach: We develop the theory of almost and $n$-almost prime ideals to the graded case. Results: We extended some basic results about almost and n-almost prime ideals to the graded case, and then we gave a relationship between n-almost graded prime ideals and weakly graded prime ideals. Conclusion: The extended results about almost and n-almost graded prime ideals allow us to classify further properties about almost graded prime ideals. 2000 AMS Mathematics Subject Classification: 13 A 02.
\end{abstract}

Key words: Graded rings, graded prime ideals, almost graded prime ideals, n-almost graded prime ideals.

\section{INTRODUCTION}

Almost prime ideals in commutative rings with $1 \neq 0$ have been introduced by ${ }^{[4]}$.

In this study we classify almost graded prime ideals in G-graded Commutative ring $\mathrm{R}$ with $1 \neq 0 \in \mathrm{R}$, where $\mathrm{G}$ is an abelian group, also we do consider some various properties of almost graded prime ideals.

Let $\mathrm{G}$ be an abelian group with identity e $\in \mathrm{G}$. By G-graded Commutative ring we mean a commutative ring $R$ with $1 \neq 0 \in R$ together with a direct sum ( as an additive group) $\mathrm{R}=\oplus_{\mathrm{g} \in \mathrm{G}} \mathrm{R}_{\mathrm{g}}$ with the property $\mathrm{R}_{\mathrm{g}} \mathrm{R}_{\mathrm{h}} \subseteq \mathrm{R}_{\mathrm{gh}} \forall \mathrm{g}, \mathrm{h} \in \mathrm{G}$. The Summands $\mathrm{R}_{\mathrm{g}}, \mathrm{g} \in \mathrm{G}$, are homogeneous Components and elements of $\mathrm{R}_{\mathrm{g}}$ are called homogeneous elements, we also write $h(R)=\bigcup_{g \in G} R_{g}$. Moreover, if $\mathrm{R}=\oplus_{g \in G} R_{g}$ is a G-graded ring with identity $0 \neq 1 \in R$, then $R_{e}$ is a subring of $R$ with $0 \neq 1 \in R_{e}$ and $R_{g}$ is an $R_{e}$-module for all $g \in G$.

Let $R=\oplus_{g \in G} R_{g}$ be a G-graded ring with $0 \neq 1 \in$ $\mathrm{R}_{\mathrm{e}}$, a (right) $\mathrm{R}$-graded module $\mathrm{M}$ is an R-module with grading $\mathrm{M}=\oplus_{\mathrm{g} \in \mathrm{G}} \mathrm{M}_{\mathrm{g}}$ as (right) $\mathrm{R}_{\mathrm{e}}$-module such that $\mathrm{m}_{\mathrm{g}}, \mathrm{r}_{\mathrm{h}} \in \mathrm{M}_{\mathrm{gh}}$ for any $\mathrm{m}_{\mathrm{g}} \in \mathrm{M}_{\mathrm{g}}, \mathrm{r}_{\mathrm{h}} \in \mathrm{R}_{\mathrm{h}}, \mathrm{g}, \mathrm{h} \in \mathrm{G}$. A (right) G-graded ideal $\mathrm{I}=\oplus_{g \in G} \mathrm{I}_{\mathrm{g}}$ is a (right) R-graded module of the G-graded ring $\mathrm{R}$.

Clearly $\{0\}$ is a graded ideal, also if I, J are G-graded ideals of $\mathrm{R}$ then:

$$
(\mathrm{I}: \mathrm{J})=\{\mathrm{a} \in \mathrm{R}: \mathrm{aJ} \subseteq \mathrm{I}\}
$$

is a G-graded ideal ${ }^{[5]}$.

A G-graded ideal I of $\mathrm{R}$ is said to be graded prime ideal if $I \neq R$ and whenever $a_{g} b_{h} \in I_{g h}$ we have $a_{g} \in I_{g}$ or $b_{h} \in$ $\mathrm{I}_{\mathrm{h}}$ and $\mathrm{I}$ is called weakly graded prime ideal if $\mathrm{I} \neq \mathrm{R}$ and whenever $0 \neq \mathrm{a}_{\mathrm{g}} \mathrm{b}_{\mathrm{h}} \in \mathrm{I}_{\mathrm{gh}}$ then either $\mathrm{a}_{\mathrm{g}} \in \mathrm{I}_{\mathrm{g}}$ or $\mathrm{b}_{\mathrm{h}} \in \mathrm{I}_{\mathrm{h}}{ }^{[3]}$.

In this study we prove that a graded ideal $I$ is an almost graded prime ideal if and only if $\mathrm{S}=\bigcup_{\mathrm{g} \in \mathrm{G}}\left(\mathrm{R}_{\mathrm{g}}-\mathrm{I}_{\mathrm{g}}\right)$ is almost multiplicatively closed. Moreover, we define an $n$-almost graded prime ideals for $\mathrm{n} \geq 2$ such that 2 -almost graded prime ideals are almost graded prime ideals and we prove that $I$ is an $n-$ almost graded prime ideal if and only if $\left(\mathrm{I}_{\mathrm{h}}: \mathrm{x}_{\mathrm{g}}\right)=\mathrm{I}_{\mathrm{hg}^{-1}}$ or $\left(\mathrm{I}_{\mathrm{h}}: \mathrm{x}_{\mathrm{g}}\right)=\left(\mathrm{I}^{\mathrm{n}} \cap \mathrm{R}_{\mathrm{h}}: \mathrm{x}_{\mathrm{g}}\right)$.

Finally, we prove that $\mathrm{I}$ is an $\mathrm{n}$-almost graded prime ideal in $\mathrm{R}$ if and only if $\mathrm{I} / \mathrm{I}^{\mathrm{n}}$ is weakly graded prime ideal in $\mathrm{R} / \mathrm{I}^{\mathrm{n}}$.

\section{MATERIALS AND METHODS}

We generalize some basic definitions and lemmas about almost and $n$-almost prime ideals to the graded case.

Definition 1: Let $\mathrm{R}$ be commutative G-graded ring, where $\mathrm{G}$ is an abelian group.

Corresponding Author: Ameer Jaber, Department of Mathematics, The Hashemite University, Zarqa, 13115, Jordan Tel: +962-07-77513484 
A proper graded ideal $\mathrm{P}$ of $\mathrm{R}$ is said to be almost graded prime ideal if:

$$
\mathrm{a}_{\mathrm{g}} \mathrm{b}_{\mathrm{h}} \in \mathrm{P}_{\mathrm{gh}}-\left[\mathrm{P}^{2} \cap \mathrm{R}_{\mathrm{gh}}\right]
$$

implies $a_{g} \in P_{g}$ or $b_{h} \in P_{h}$.

Example: Let $\mathrm{R}=[\mathrm{i}]$ be a $\mathrm{Z}_{2}$-graded ring and let $\mathrm{R}_{0}=\mathrm{Z}, \mathrm{R}_{1}=\mathrm{iZ}$. Then $\mathrm{R}$ is commutative $\mathrm{Z}_{2}$-graded ring with $1 \in \mathrm{R}_{\overline{0}}$. One can easily check that the graded ideal:

$$
P=2 R=\{2 a+2 b i: a, b \in Z\}
$$

With $\mathrm{P}_{0}=2 \mathrm{Z}$ and $\mathrm{P}_{1}=2 \mathrm{Zi}$ is an almost graded prime ideal in $\mathrm{R}$, but $\mathrm{P}$ as an ideal in $\mathrm{R}$ is not almost prime ideal, since $(1-\mathrm{i})(1+\mathrm{i})=2 \in \mathrm{P}-\mathrm{P}^{2}$ and $1-i, 1+i \notin P$.

Lemma 1: Le P, A, B be arbitrary graded ideals of a commutative graded ring $R$. If $P_{g} \subseteq A_{g} \cup B_{g}$, then $\mathrm{P}_{\mathrm{g}} \subseteq \mathrm{A}_{\mathrm{g}}$ or $\mathrm{P}_{\mathrm{g}} \subseteq \mathrm{B}_{\mathrm{g}}$. In particular, if $\mathrm{P}_{\mathrm{g}}=\mathrm{A}_{\mathrm{g}} \cup \mathrm{B}_{\mathrm{g}}$, then $\mathrm{P}_{\mathrm{g}}=\mathrm{A}_{\mathrm{g}}$ or $\mathrm{P}_{\mathrm{g}}=\mathrm{B}_{\mathrm{g}}$.

Proof: Assume that $\mathrm{P}_{\mathrm{g}} \subseteq \mathrm{A}_{\mathrm{g}} \cup \mathrm{B}_{\mathrm{g}}$, but $\mathrm{P}_{\mathrm{g}} \not \subset \mathrm{A}_{\mathrm{g}}$ and $\mathrm{P}_{\mathrm{g}} \not \subset \mathrm{B}_{\mathrm{g}}$. So we have $\mathrm{a}_{\mathrm{g}}, \mathrm{b}_{\mathrm{g}} \in \mathrm{P}_{\mathrm{g}}$ where $\mathrm{a}_{\mathrm{g}} \notin \mathrm{B}_{\mathrm{g}}$ and $\mathrm{b}_{\mathrm{g}} \notin \mathrm{A}_{\mathrm{g}}$, therefore $\mathrm{a}_{\mathrm{g}} \in \mathrm{A}_{\mathrm{g}}$ and $\mathrm{b}_{\mathrm{g}} \in \mathrm{B}_{\mathrm{g}}$. But:

$$
\mathrm{a}_{\mathrm{g}}+\mathrm{b}_{\mathrm{g}} \in \mathrm{P}_{\mathrm{g}} \subseteq \mathrm{A}_{\mathrm{g}} \cup \mathrm{B}_{\mathrm{g}}
$$

so $a_{\mathrm{g}}+\mathrm{b}_{\mathrm{g}} \in \mathrm{A}_{\mathrm{g}}$ or $\mathrm{a}_{\mathrm{g}}+\mathrm{b}_{\mathrm{g}} \in \mathrm{B}_{\mathrm{g}}$. In the first case $\mathrm{b}_{\mathrm{g}} \in \mathrm{A}_{\mathrm{g}}$ while the second case $\mathrm{a}_{\mathrm{g}} \in \mathrm{B}_{\mathrm{g}}$, both contradictions. The second statement follows because $P_{g}=A_{g} \cup B_{g}$ implies $\mathrm{A}_{\mathrm{g}} \subseteq \mathrm{P}_{\mathrm{g}}$ or $\mathrm{B}_{\mathrm{g}} \subseteq \mathrm{P}_{\mathrm{g}}$.

Lemma 2: Let $\mathrm{R}$ be commutative G-graded ring, let I be a graded ideal in $R$ and let $x_{\mathrm{g}} \notin \mathrm{I}_{\mathrm{g}}$ for some $\mathrm{g} \in \mathrm{G}$. Then $\left(\mathrm{I}: \mathrm{x}_{\mathrm{g}}\right)$ is a G-graded ideal in $\mathrm{R}$, Where:

$$
\left(\mathrm{I}: \mathrm{x}_{\mathrm{g}}\right)=\left\{\mathrm{r} \in \mathrm{R}: \mathrm{rx}_{\mathrm{g}} \in \mathrm{I}\right\}
$$

Proof: First of all we show that $\left(\mathrm{I}: \mathrm{x}_{\mathrm{g}}\right)=\oplus_{\mathrm{h} \in \mathrm{G}}\left(\mathrm{I}_{\mathrm{h}}: \mathrm{x}_{\mathrm{g}}\right)$. One can easily see that $\oplus_{\mathrm{h} \in \mathrm{G}}\left(\mathrm{I}_{\mathrm{h}}: \mathrm{x}_{\mathrm{g}}\right) \subseteq\left(\mathrm{I}: \mathrm{x}_{\mathrm{g}}\right)$. Conversely, let $r \in\left(I: x_{g}\right)$, then $r_{x_{g}} \in I$ which implies that $\mathrm{r}_{\mathrm{h}} \mathrm{x}_{\mathrm{g}} \in \mathrm{I}_{\mathrm{hg}}$ for all $\mathrm{h} \in \mathrm{G}$, thus $\mathrm{r}_{\mathrm{h}} \in\left(\mathrm{I}_{\mathrm{hg}}: \mathrm{x}_{\mathrm{g}}\right)$ for all $h \in G$. So:

$$
\mathrm{r}=\sum \mathrm{r}_{\mathrm{h}^{\prime}} \in\left(\mathrm{I}_{\mathrm{h}_{\mathrm{g}}}: \mathrm{x}_{\mathrm{g}}\right)=\Theta_{\mathrm{h} \in \mathrm{G}}\left(\mathrm{I}_{\mathrm{h}}: \mathrm{x}_{\mathrm{g}}\right)
$$

Therefore:

$$
\left(\mathrm{I}: \mathrm{x}_{\mathrm{g}}\right)=\oplus_{\mathrm{h} \in \mathrm{G}}\left(\mathrm{I}_{\mathrm{h}}: \mathrm{x}_{\mathrm{g}}\right)
$$

Next we show that (I: $\left.x_{g}\right)$ is a G-graded ideal. It is easy to see that $\left(\mathrm{I}_{\mathrm{h}}: \mathrm{x}_{\mathrm{g}}\right)$ is closed under addition. Now let $\mathrm{a}_{\mathrm{h}} \in\left(\mathrm{I}_{\mathrm{hg}}: \mathrm{x}_{\mathrm{g}}\right)$ and let $\mathrm{r}_{\mathrm{h}^{\prime}} \in \mathrm{R}_{\mathrm{h}^{\mathrm{h}}}$, then $\quad \mathrm{r}_{\mathrm{h}} \mathrm{a}_{\mathrm{h}} \mathrm{x}_{\mathrm{g}} \in \mathrm{r}_{\mathrm{h}} \mathrm{I}_{\mathrm{hg}} \subseteq \mathrm{I}_{\text {hing }}, \quad$ therefore $\mathrm{r}_{\mathrm{h}}, \mathrm{a}_{\mathrm{h}} \in\left(\mathrm{I}_{\mathrm{hhg}}: \mathrm{x}_{\mathrm{g}}\right) \subseteq\left(\mathrm{I}: \mathrm{x}_{\mathrm{g}}\right)$. Thus (I: $\left.\mathrm{x}_{\mathrm{g}}\right)$ is a G-graded ideal.

We can also prove the lemma above in another way, by showing that $\left(\mathrm{I}: \mathrm{x}_{\mathrm{g}}\right)=\left(\mathrm{I}: \mathrm{Rx}_{\mathrm{g}}\right)$, where $\mathrm{Rx}_{\mathrm{g}}=\left\{\mathrm{rx}_{\mathrm{g}}: \mathrm{r} \in \mathrm{R}\right\}$ is a G-graded ideal in $\mathrm{R}$, so by ${ }^{[4]}$ (I: $\mathrm{x}_{\mathrm{g}}$ ) is a G-graded ideal.

Now by the lemma above if $I$ is a graded ideal in a is a G-graded ring $R$ and $x_{g} \notin I_{g}$ for some $g \in G$ then (I: $\mathrm{x}_{\mathrm{g}}$ ) and $\left(\mathrm{I}^{2}: \mathrm{x}_{\mathrm{g}}\right)$ are graded ideals in $\mathrm{R}$. Thus we have the following result about almost graded prime ideals.

Theorem 1: For a proper graded ideal I of a G-graded ring $\mathrm{R}$ the following assertions are equivalent.

a) I is almost graded prime ideal.

b) For $x_{g} \in R_{g}-I_{g},\left(I_{h}: x_{g}\right)=I_{h^{-1}} U\left(I^{2} \cap R_{h}: x_{g}\right)$

c) For $\quad x_{g} \in R_{g}-I_{g}, \quad\left(I_{h}: x_{g}\right)=I_{h^{-1}} \quad$ or $\left(\mathrm{I}_{\mathrm{h}}: \mathrm{x}_{\mathrm{g}}\right)=\left(\mathrm{I}^{2} \cap \mathrm{R}_{\mathrm{h}}: \mathrm{x}_{\mathrm{g}}\right)$

d) For $\mathrm{R}_{\mathrm{e}}$-modules $\mathrm{A}_{\mathrm{g}} \subseteq \mathrm{R}_{\mathrm{g}} \quad$ and $\quad \mathrm{B}_{\mathrm{h}} \subseteq \mathrm{R}_{\mathrm{h}}$ with $A_{\mathrm{g}} B_{\mathrm{h}} \subseteq \mathrm{I}_{\mathrm{gh}}$, but $\mathrm{A}_{\mathrm{g}} \mathrm{B}_{\mathrm{h}} \not \subset \mathrm{I}^{2} \cap \mathrm{R}_{\mathrm{gh}}$, then $\mathrm{A}_{\mathrm{g}} \subseteq \mathrm{I}_{\mathrm{g}}$ or $\mathrm{B}_{\mathrm{h}} \subseteq \mathrm{I}_{\mathrm{h}}$

\section{Proof:}

- (a) $\Rightarrow$ (b) Let $\mathrm{y}_{\mathrm{hg}^{-1}} \in\left(\mathrm{I}_{\mathrm{h}}: \mathrm{x}_{\mathrm{g}}\right)$, then $\mathrm{y}_{\mathrm{hg}^{-1}} \mathrm{x}_{\mathrm{g}} \in \mathrm{I}_{\mathrm{h}}$, if $\mathrm{y}_{\mathrm{hg}^{-1}} \mathrm{x}_{\mathrm{g}} \notin \mathrm{I}^{2} \cap \mathrm{R}_{\mathrm{h}}$, then $\mathrm{y}_{\mathrm{hg}^{-1}} \mathrm{x}_{\mathrm{g}} \in \mathrm{I}_{\mathrm{h}}-\left(\mathrm{I}^{2} \cap \mathrm{R}_{\mathrm{h}}\right)$, but $\mathrm{I}$ is almost graded prime ideal, so $\mathrm{y}_{\mathrm{hg}^{-1}} \mathrm{x}_{\mathrm{g}} \in \mathrm{I}_{\mathrm{hg}^{-1}}$ since $\mathrm{x}_{\mathrm{g}} \notin \mathrm{I}_{\mathrm{g}}, \quad$ but if $\quad \mathrm{y}_{\mathrm{hg}^{-1}} \mathrm{x}_{\mathrm{g}} \in \mathrm{I}^{2} \cap \mathrm{R}_{\mathrm{h}}$, then $\mathrm{y}_{\mathrm{hg}^{-1}} \in\left(\mathrm{I}^{2} \cap \mathrm{R}_{\mathrm{h}}: \mathrm{x}_{\mathrm{g}}\right), \quad$ so $\left(\mathrm{I}_{\mathrm{h}}: \mathrm{x}_{\mathrm{g}}\right) \subseteq \mathrm{I}_{\mathrm{hg}^{-1}} \subset\left(\mathrm{I}^{2} \cap \mathrm{R}_{\mathrm{h}}: \mathrm{x}_{\mathrm{g}}\right)$, but $\mathrm{I}^{2} \cap \mathrm{R}_{\mathrm{h}} \subseteq \mathrm{I}_{\mathrm{h}}$ and $\mathrm{I}_{\mathrm{hg}^{-1}} \subseteq\left(\mathrm{I}_{\mathrm{h}}: \mathrm{x}_{\mathrm{g}}\right) \quad$ thus $\quad \mathrm{I}_{\mathrm{hg}^{-1}} \mathrm{U}\left(\mathrm{I}^{2} \cap \mathrm{R}_{\mathrm{h}}: \mathrm{x}_{\mathrm{g}}\right) \subseteq\left(\mathrm{I}_{\mathrm{h}}: \mathrm{x}_{\mathrm{g}}\right)$ and hence

$$
\left(\mathrm{I}_{\mathrm{h}}: \mathrm{x}_{\mathrm{g}}\right)=\mathrm{I}_{\mathrm{hg}^{-1}} \mathrm{U}\left(\mathrm{I}^{2} \cap \mathrm{R}_{\mathrm{h}}: \mathrm{x}_{\mathrm{g}}\right)
$$


- $\quad$ (b) $\Rightarrow$ (c) Follows from Lemma 1 and 2

- (c) $\Rightarrow$ (d) Let $\mathrm{A}_{\mathrm{g}} \subseteq \mathrm{R}_{\mathrm{g}}, \mathrm{B}_{\mathrm{h}} \subseteq \mathrm{R}_{\mathrm{h}}$ with $\mathrm{A}_{\mathrm{g}} \mathrm{B}_{\mathrm{h}} \subseteq \mathrm{I}_{\mathrm{gh}}$, but $A_{g} B_{h} \not \subset I^{2} \cap R_{\text {gh }}$. We show that $A_{g} \subseteq I_{g}$ or $\mathrm{B}_{\mathrm{h}} \subseteq \mathrm{I}_{\mathrm{h}}$. Suppose on contrary that $\mathrm{A}_{\mathrm{g}} \not \subset \mathrm{I}_{\mathrm{g}}$ and $\mathrm{B}_{\mathrm{h}} \not \subset \mathrm{I}_{\mathrm{h}}$, then for $\mathrm{a}_{\mathrm{g}} \in \mathrm{A}_{\mathrm{g}}-\mathrm{I}_{\mathrm{g}}, \mathrm{a}_{\mathrm{g}} \mathrm{B}_{\mathrm{h}} \subseteq \mathrm{I}_{\mathrm{gh}}$ which implies that $\mathrm{B}_{\mathrm{h}} \subseteq\left(\mathrm{I}_{\mathrm{gh}}: \mathrm{a}_{\mathrm{g}}\right)$, but since $\mathrm{B}_{\mathrm{h}} \not \subset \mathrm{I}_{\mathrm{h}}$ we have $\left(I_{g h}: a_{g}\right) \neq I_{h}$. Thus by part (c) of the theorem $\left(\mathrm{I}_{\mathrm{gh}}: \mathrm{a}_{\mathrm{g}}\right)=\left(\mathrm{I}^{2} \cap \mathrm{R}_{\mathrm{h}}: \mathrm{a}_{\mathrm{g}}\right)$ and so $\mathrm{B}_{\mathrm{h}} \subseteq\left(\mathrm{I}^{2} \cap \mathrm{R}_{\mathrm{gh}}: \mathrm{a}_{\mathrm{g}}\right)$. Hence $a_{g} B_{h} \subset I^{2} \cap R_{g h}$. Similarly, if $b_{h} \in B_{h}-I_{h}$, then $A_{g} b_{h} \subseteq I^{2} \cap R_{g h}$. Finally, for any $a_{g} \in A_{g} \cap I_{g}$ and $b_{h} \in B_{h} \cap I_{h}$ then $a_{g} b_{h} \in I^{2} \cap R_{g h}$. Therefore $\mathrm{A}_{\mathrm{g}} \mathrm{b}_{\mathrm{h}} \subseteq \mathrm{I}^{2} \cap \mathrm{R}_{\mathrm{gh}}$, a contradiction. Thus $\mathrm{A}_{\mathrm{g}} \subseteq \mathrm{R}_{\mathrm{g}}$ or $\mathrm{B}_{\mathrm{h}} \subseteq \mathrm{I}_{\mathrm{h}}$

- (d) $\Rightarrow$ (a) Let $a_{\mathrm{g}} \mathrm{b}_{\mathrm{h}} \in \mathrm{I}_{\mathrm{gh}}-\mathrm{I}^{2} \cap \mathrm{R}_{\mathrm{gh}}$ and let $A_{g}=a_{g} R_{e}, B_{h}=b_{h} R_{e}$, where $e$ is the identity in G. Then $\mathrm{A}_{\mathrm{g}} \mathrm{B}_{\mathrm{h}} \subseteq \mathrm{I}_{\text {gh }}$, but $\mathrm{A}_{\mathrm{g}} \mathrm{B}_{\mathrm{h}} \not \subset \mathrm{I}^{2} \cap \mathrm{R}_{\text {gh }}$ so by part (d) of the theorem $\mathrm{A}_{\mathrm{g}} \subseteq \mathrm{I}_{\mathrm{g}}$ or $\mathrm{B}_{\mathrm{h}} \subseteq \mathrm{I}_{\mathrm{h}}$ and this implies that $a_{g} \in I_{g}$ or $b_{h} \in I_{h}$ which means that $I$ is almost graded prime ideal

Definition 2: Let $R$ be a G-graded ring. Then a nonempty subset $\mathrm{S}$ of $\mathrm{h}(\mathrm{R})$ is called gradedmultiplicatively closed whenever $a, b \in S$ then $a b \in S$.

Lemma 3: A grade ideal $I$ of a $G$-graded ring $R$ is a graded prime ideal if and only if $S=\bigcup_{g \in G}\left(R_{g}-I_{g}\right)$ is graded-multiplicatively closed.

Proof: $(\Rightarrow)$ Suppose $\mathrm{I}$ is a graded prime ideal and let $\mathrm{x}$, $y \in S$, then $x=a_{g} \in R_{g}-I_{g}, y=b_{h} \in R_{h}-I_{h}$ for some $g, h$ $\in G$. Now $x y=a_{g} b_{h} \in S$, if not then $x y=a_{g} b_{h} \notin R_{g h}-I_{g h}$, which means that $x y=a_{g} b_{h} \in I_{g h}$, since $I$ is graded prime ideal $a_{g} \in I_{g}$ or $b_{h} \in I_{h}$ a contradiction. Hence $S$ is graded-multiplicatively closed.

$(\Leftarrow)$ Suppose $\mathrm{S}$ is graded-multiplicatively closed and let $\mathrm{a}_{\mathrm{g}} \mathrm{b}_{\mathrm{h}} \in \mathrm{I}_{\mathrm{gh}}$, then $\mathrm{a}_{\mathrm{g}} \mathrm{b}_{\mathrm{h}} \notin \mathrm{R}_{\mathrm{gh}}-\mathrm{I}_{\mathrm{gh}}$ which means that $a_{g} b_{h} \notin S$ and so $a_{g} \notin R_{g}-I_{g}$ or $b_{h} \notin R_{h}-I_{h}$ and this is equivalent to say that $a_{g} \in I_{g}$ or $b_{h} \in I_{h}$.

Definition 3: Let $\mathrm{R}$ be a G-graded ring and let $\mathrm{I}$ be a graded ideal of $\mathrm{R}$. Then $\mathrm{I}$ is called weakly graded prime ideal of $R$ if $0 \neq a_{g} b_{h} \in I_{g h}$, then $a_{g} \in I_{g}$ or $b_{h} \in I_{h}$.
Definition 4: Let $\mathrm{R}$ be a G-graded ring. Then a non empty subset $S$ of $h(R)$ is called weakly gradedmultiplicatively closed if $\mathrm{a}, \mathrm{b} \in \mathrm{S}$ then $\mathrm{ab} \in \mathrm{S}$ or $\mathrm{ab}=0$.

Lemma 4: A graded ideal $I$ of a G-graded ring $R$ is weakly graded prime if and only if $S=\bigcup_{g \in G}\left(R_{g}-I_{g}\right)$ is weakly graded-multiplicatively closed.

Proof: $(\Rightarrow)$ Suppose I is weakly graded prime ideal and let $x, y \in S$, then $x=a_{g} \in R_{g}-I_{g}, y=b_{h} \in R_{h}-I_{h}$ for some $g, h \in G$, thus $a_{g} \notin I_{g}$ and $b_{h} \notin I_{h}$. If $x y=a_{g} b_{h} \neq 0$, then $a_{\mathrm{g}} b_{\mathrm{h}} \notin \mathrm{I}_{\text {gh }}$, since $\mathrm{I}$ is weakly graded prime ideal, which implies that $x y=a_{g} b_{h} \in R_{\text {gh }}-I_{\text {gh }} \subseteq S$. Thus $x y=0$ or $x y \in S$. Hence $S$ is weakly graded-multiplicatively closed.

$(\Leftarrow)$ Suppose $\mathrm{S}$ is weakly graded-multiplicatively closed and let $0 \neq a_{g} b_{h} \in I_{g h}$, then $a_{g} b_{h} \notin R_{g h}-I_{g h}$, so $a_{\mathrm{g}} b_{\mathrm{h}} \notin \mathrm{S}$ which implies $\mathrm{a}_{\mathrm{g}} \notin \mathrm{R}_{\mathrm{g}}-\mathrm{I}_{\mathrm{g}}$ or $\mathrm{b}_{\mathrm{h}} \notin \mathrm{R}_{\mathrm{h}}-\mathrm{I}_{\mathrm{h}}$. Thus $a_{g} \in I_{g}$ or $b_{h} \in I_{h}$, hence $I$ is weakly graded prime ideal.

Definition 5: If $A \neq \Phi$ is a subset of a graded ring $R$, then we define $\mathrm{A}^{2}$ to be the smallest graded ideal in $\mathrm{R}$ Containing $\{a b: a, b \in A\}$.

Lemma 5: Let $R$ be a G-graded ring and let $I$ be a graded ideal in R. If:

$$
S=\bigcup_{g \in G}\left(R_{g}-I_{g}\right)
$$

Then:
(a) $(h(R)-S) \cap R_{h}=I_{h}$ for all $h \in G$
(b) $(\mathrm{h}(\mathrm{R})-\mathrm{S})^{2}=\mathrm{I}^{2}$

\section{Proof:}

(a) Let $x_{h} \in I_{h}$ then $x_{h} \notin R_{h}-I_{h}$ which means $x_{h} \notin S$, thus $\quad x_{h} \in(h(R)-S) \cap R_{h}$. Conversely, let $x_{h} \in(h(R)-S) \cap R_{h}, \quad$ then $\quad x_{h} \notin S \cap R_{h}$, hence $x_{h} \notin R_{h}-I_{h}$ which means that $x_{h} \in I_{h}$.

(b) $(\mathrm{h}(\mathrm{R})-\mathrm{S})^{2}=\mathrm{I}^{2}$ follows from (a)

Definition 6: Let $R$ be a G-graded ring. Then a nonempty subset of $\mathrm{R}$ is called almost gradedmultiplicatively closed if $\mathrm{a}, \mathrm{b} \in \mathrm{S}$ implies:

$$
a b \in S \text { or } a b \in(h(R)-S)^{2}
$$

Lemma 6: A graded ideal $I$ of a G-graded ring $R$ is almost graded prime ideal if and only if 
$\mathrm{S}=\bigcup_{\mathrm{g} \in \mathrm{G}}\left(\mathrm{R}_{\mathrm{g}}-\mathrm{I}_{\mathrm{g}}\right)$ is almost graded-multiplicatively closed.

Proof: $(\Rightarrow)$ Suppose that $I$ is almost graded prime ideal and let $x, y \in S$, then $x=a_{g} \in R_{g}-I_{g}, y=b_{h} \in R_{h}-I_{h}$ for some $g, h \in G$. So $a_{g} \notin I_{g}$ and $b_{h} \notin I_{h}$, hence $a_{g} b_{h} \notin I_{g h}-\left(I^{2} \cap R_{g h}\right) . \quad$ Therefore $\quad a_{g} b_{h} \notin I_{g h} \quad$ or $\mathrm{a}_{\mathrm{g}} \mathrm{b}_{\mathrm{h}} \in\left(\mathrm{I}^{2} \cap \mathrm{R}_{\mathrm{gh}}\right)$ which implies that $\mathrm{a}_{\mathrm{g}} \mathrm{b}_{\mathrm{h}} \in \mathrm{R}_{\mathrm{gh}}-\mathrm{I}_{\mathrm{gh}} \subseteq \mathrm{S}$ or $a_{\mathrm{g}} b_{\mathrm{h}} \in \mathrm{I}^{2} \cap \mathrm{R}_{\mathrm{gh}}$, but by Lemma $5,(\mathrm{~h}(\mathrm{R})-\mathrm{S})^{2}=\mathrm{I}^{2}$, where $h(R)=\bigcup_{g \in G} R_{g}$, so $a_{g} b_{h} \in S$ or $a_{g} b_{h} \in(h(R)-S)^{2}$, thus $\mathrm{S}$ is almost graded-multiplicatively closed.

$(\Leftarrow)$ Suppose $\mathrm{S}$ is an almost gradedmultiplicatively closed and let $\mathrm{a}_{\mathrm{g}} \mathrm{b}_{\mathrm{h}} \in \mathrm{I}_{\mathrm{gh}}-\left(\mathrm{I}^{2} \cap \mathrm{R}_{\mathrm{gh}}\right)$. Then $a_{g} b_{h} \notin I^{2} \cap R_{\text {gh }}$, we want to show that $a_{g} \in I_{g}$ or $b_{h} \in I_{h}$. Suppose on contrary that $a_{g} \in R_{g}-I_{g}$ and $b_{h} \in R_{h}-I_{h}$, then $a_{g}$ and $b_{h}$ are in $S$ and since $S$ is almost graded-multiplicatively closed, $\mathrm{a}_{\mathrm{g}} \mathrm{b}_{\mathrm{h}} \in \mathrm{S}$ or $a_{g} b_{h} \in(h(R)-S)^{2}$. But $a_{g} b_{h} \in I_{g h}$ which means that $a_{g} b_{h} \notin S$. So $a_{g} b_{h} \in(h(R)-S)^{2}$, but by Lemma 5 , $(h(R)-S)^{2}=I^{2} \quad$ which means that $a_{g} b_{h} \in I^{2} \cap R_{g h}$ contradiction. Therefore $a_{g} \in I_{g}$ or $b_{h} \in I_{h}$ and hence $I$ is almost graded prime ideal.

Definition 7: Let $\mathrm{R}$ be a commutative G-graded ring, where $G$ is an abelian group. A proper graded ideal $P$ of $\mathrm{R}$ is said to be $\mathrm{n}$-almost graded prime ideal if:

$$
a_{g} b_{h} \in P_{g h}-\left[P^{n} \cap R_{g h}\right]
$$

implies $\mathrm{a}_{\mathrm{g}} \in \mathrm{P}_{\mathrm{g}}$ or $\mathrm{b}_{\mathrm{h}} \in \mathrm{P}_{\mathrm{h}}$.

\section{RESULTS AND DISCUSSION}

By Lemma 2 if $I$ is a graded ideal in a G-graded ring $R$ and $x_{g} \notin I_{g}$ for some $g \in G$ then ( $I: x_{g}$ ) and $\left(\mathrm{I}^{\mathrm{n}}: \mathrm{x}_{\mathrm{g}}\right)$ are graded ideals in $\mathrm{R}$. So 2-almost graded prime ideals are the same as almost graded prime ideals. The following result will characterize n-almost graded prime ideals.

Theorem 2: For a proper graded ideal I of a graded ring $\mathrm{R}$ the following assertions are equivalent.

(a) I is n-almost graded prime ideal

(b) For $x_{g} \in R_{g}-I_{g},\left(I_{h}: x_{g}\right)=I_{h^{-1}} U\left(I^{n} \cap R_{h}: x_{g}\right)$. (c) For

$$
x_{g} \in R_{g}-I_{g},\left(I_{h}: x_{g}\right)=I_{h^{-1}}
$$

$\left(\mathrm{I}_{\mathrm{h}}: \mathrm{x}_{\mathrm{g}}\right)=\left(\mathrm{I}^{\mathrm{n}} \cap \mathrm{R}_{\mathrm{h}}: \mathrm{x}_{\mathrm{g}}\right)$

(d) For $\mathrm{R}_{\mathrm{e}}$-modules $\mathrm{A}_{\mathrm{g}} \subseteq \mathrm{I}_{\mathrm{g}}$ and $\mathrm{B}_{\mathrm{h}} \subseteq \mathrm{I}_{\mathrm{h}}$ with $\mathrm{A}_{\mathrm{g}} \mathrm{B}_{\mathrm{h}} \subseteq \mathrm{I}_{\mathrm{gh}}$, but $\mathrm{A}_{\mathrm{g}} \mathrm{B}_{\mathrm{h}} \not \subset \mathrm{I}^{\mathrm{n}} \cap \mathrm{R}_{\mathrm{gh}}$, then $\mathrm{A}_{\mathrm{g}} \subseteq \mathrm{I}_{\mathrm{g}}$ or $\mathrm{B}_{\mathrm{h}} \subseteq \mathrm{I}_{\mathrm{h}}$

\section{Proof:}

- (a) $\Rightarrow$ (b) Let $\mathrm{y}_{\mathrm{hg}^{-1}} \in\left(\mathrm{I}_{\mathrm{h}}: \mathrm{x}_{\mathrm{g}}\right)$, then $\mathrm{y}_{\mathrm{hg}^{-1}} \mathrm{x}_{\mathrm{g}} \in \mathrm{I}_{\mathrm{h}}$, if $\mathrm{y}_{\mathrm{hg}^{-1}} \mathrm{x}_{\mathrm{g}} \in \mathrm{I}^{\mathrm{n}} \cap \mathrm{R}_{\mathrm{h}}$, then $\mathrm{y}_{\mathrm{hg}^{-1}} \in\left(\mathrm{I}^{\mathrm{n}} \cap \mathrm{R}_{\mathrm{h}}: \mathrm{x}_{\mathrm{g}}\right)$, while if $\mathrm{y}_{\mathrm{hg}^{-1}} \mathrm{x}_{\mathrm{g}} \notin \mathrm{I}^{\mathrm{n}} \cap \mathrm{R}_{\mathrm{h}}$, then $\mathrm{y}_{\mathrm{hg}^{-1}} \mathrm{x}_{\mathrm{g}} \in \mathrm{I}_{\mathrm{h}}-\left(\mathrm{I}^{\mathrm{n}} \cap \mathrm{R}_{\mathrm{h}}\right)$ and since $I$ is $n$-almost graded prime ideal and $x_{g} \notin I_{g}$, then $\mathrm{y}_{\mathrm{hg}^{-1}} \in \mathrm{I}_{\mathrm{hg}^{-1}}$, so $\left(\mathrm{I}_{\mathrm{h}}: \mathrm{x}_{\mathrm{g}}\right) \subseteq \mathrm{I}_{\mathrm{hg}^{-1}} \cup\left(\mathrm{I}^{\mathrm{n}} \cap \mathrm{R}_{\mathrm{h}}: \mathrm{x}_{\mathrm{g}}\right)$, but $\quad \mathrm{I}^{\mathrm{n}} \cap \mathrm{R}_{\mathrm{h}} \subseteq \mathrm{I}_{\mathrm{h}} \quad$ and $\quad \mathrm{I}_{\mathrm{hg}^{-1}} \subseteq\left(\mathrm{I}_{\mathrm{h}}: \mathrm{x}_{\mathrm{g}}\right), \quad$ so $\mathrm{I}_{\mathrm{hg}^{-1}} \mathrm{U}\left(\mathrm{I}^{\mathrm{n}} \cap \mathrm{R}_{\mathrm{h}}: \mathrm{x}_{\mathrm{g}}\right) \subseteq\left(\mathrm{I}_{\mathrm{h}}: \mathrm{x}_{\mathrm{g}}\right) \quad$ and hence $\left(\mathrm{I}_{\mathrm{h}}: \mathrm{x}_{\mathrm{g}}\right)=\mathrm{I}_{\mathrm{hg}^{-1}} \mathrm{U}\left(\mathrm{I}^{\mathrm{n}} \cap \mathrm{R}_{\mathrm{h}}: \mathrm{x}_{\mathrm{g}}\right)$.

- $\quad(b) \Rightarrow$ (c) Since $\left(\mathrm{I}^{\mathrm{n}} \cap \mathrm{x}_{\mathrm{g}}\right)$ and I are G-graded ideals and:

$$
\left(I_{h}: x_{g}\right)=I_{h^{-1}} U\left(I^{n} \cap R_{h}: x_{g}\right)
$$

then by Lemma 1:

$$
\left(I_{h}: x_{g}\right)=I_{h^{-1}} \text { or }\left(I_{h}: x_{g}\right)=\left(I^{n} \cap R_{h}: x_{g}\right)
$$

- (c) $\Rightarrow$ (d) Let $\mathrm{A}_{\mathrm{g}} \subseteq \mathrm{I}_{\mathrm{g}}, \mathrm{B}_{\mathrm{h}} \subseteq \mathrm{I}_{\mathrm{h}}$ with $\mathrm{A}_{\mathrm{g}} \mathrm{B}_{\mathrm{h}} \subseteq \mathrm{I}_{\text {gh }}$, but $\mathrm{A}_{\mathrm{g}} \mathrm{B}_{\mathrm{h}} \not \subset \mathrm{I}^{\mathrm{n}} \cap \mathrm{R}_{\mathrm{gh}}$. We show that $\mathrm{A}_{\mathrm{g}} \subseteq \mathrm{I}_{\mathrm{g}}$ or $\mathrm{B}_{\mathrm{h}} \subseteq \mathrm{I}_{\mathrm{h}}$. Suppose on contrary that $\mathrm{A}_{\mathrm{g}} \not \subset \mathrm{I}_{\mathrm{g}}$ and $\mathrm{B}_{\mathrm{h}} \not \subset \mathrm{I}_{\mathrm{h}}$, then let $\mathrm{a}_{\mathrm{g}} \in \mathrm{A}_{\mathrm{g}}-\mathrm{I}_{\mathrm{g}}, \mathrm{a}_{\mathrm{g}} \mathrm{B}_{\mathrm{h}} \subseteq \mathrm{I}_{\mathrm{gh}}$ and hence $\mathrm{B}_{\mathrm{h}} \subseteq\left(\mathrm{I}_{\mathrm{gh}}: \mathrm{a}_{\mathrm{g}}\right)$, but $\mathrm{B}_{\mathrm{h}} \not \subset \mathrm{I}_{\mathrm{h}}$, so by part (c) of the theorem $\left(I_{g h}: a_{g}\right)=\left(I^{n} \cap R_{g h}: a_{g}\right)$ and therefore $\mathrm{B}_{\mathrm{h}} \subseteq\left(\mathrm{I}^{\mathrm{n}} \cap \mathrm{R}_{\mathrm{gh}}: \mathrm{a}_{\mathrm{g}}\right) \quad$ which implies that $\mathrm{a}_{\mathrm{g}} \mathrm{B}_{\mathrm{h}} \subset \mathrm{I}^{\mathrm{n}} \cap \mathrm{R}_{\mathrm{gh}}$. Next let $\mathrm{a}_{\mathrm{g}} \in \mathrm{A}_{\mathrm{g}} \cap \mathrm{I}_{\mathrm{g}}$, choose $a_{g}^{\prime} \in A_{g} \cap I_{g}$, then $a_{g}+a_{g}^{\prime} \in A_{g}-I_{g}$ so by the first case $a_{g}^{\prime} B_{h}$ and $\left(a_{g}+a_{g}^{\prime}\right) B_{h}$ are subsets of $I^{n} \cap R_{g h}$. Thus for any $b_{h} \in B_{h}, a_{g}^{\prime} b_{h}$ and $\left(a_{g}+a_{g}^{\prime}\right) b_{h}$ are in $I^{n} \cap R_{g h}, \quad$ so $\quad a_{g} b_{h} \in I^{n} \cap R_{g h} \quad$ and hence $\mathrm{A}_{\mathrm{g}} \mathrm{B}_{\mathrm{h}} \subseteq \mathrm{I}^{\mathrm{n}} \cap \mathrm{R}_{\mathrm{gh}}$ a contradiction. Therefore $\mathrm{A}_{\mathrm{g}} \subseteq \mathrm{I}_{\mathrm{g}}$ or $\mathrm{B}_{\mathrm{h}} \subseteq \mathrm{I}_{\mathrm{h}}$.

- (d) $\Rightarrow$ (a) Let $a_{\mathrm{g}} \mathrm{b}_{\mathrm{h}} \in \mathrm{I}_{\mathrm{gh}}-\mathrm{I}^{\mathrm{n}} \cap \mathrm{R}_{\mathrm{gh}}$ and let $A_{g}=a_{g} R_{e}, B_{h}=b_{h} R_{e}$, where $e$ is the identity in $G$. 
Then $\mathrm{A}_{\mathrm{g}} \mathrm{B}_{\mathrm{h}} \subseteq \mathrm{I}_{\text {gh }}$, but $\mathrm{A}_{\mathrm{g}} \mathrm{B}_{\mathrm{h}} \not \subset \mathrm{I}^{\mathrm{n}} \cap \mathrm{R}_{\text {gh }}$ so by part (d) of the theorem $\mathrm{A}_{\mathrm{g}} \subseteq \mathrm{I}_{\mathrm{g}}$ or $\mathrm{B}_{\mathrm{h}} \subseteq \mathrm{I}_{\mathrm{h}}$ and this implies that $a_{g} \in I_{g}$ or $b_{h} \in P_{h}$ which means that $I$ is $n$ almost graded prime ideal

The following result shows the relationship between $\mathrm{n}$-almost graded prime ideals and weakly prime ideals.

Theorem 3: Let $\mathrm{R}$ be a commutative G-graded ring, then a graded ideal Iof $\mathrm{R}$ is an $\mathrm{n}$-almost graded prime ideal if and only if $I / I^{\mathrm{n}}$ is weakly graded prime ideal in the $\mathrm{G}$-graded ring $\mathrm{R} / \mathrm{I}^{\mathrm{n}}$.

Proof: Suppose I is an n-almost graded prime ideal in $\mathrm{R}$ and let:

$$
0 \neq\left(a_{g}+I^{n}\right)\left(b_{h}+I^{n}\right) \in\left(I / I^{n}\right)_{g h}
$$

then $0 \neq a_{g} b_{h}+I^{n} \in\left(I / I^{n}\right)_{g h}$ which implies that $a_{g} b_{h} \in I_{g h}$ and $a_{g} b_{h} \notin I^{n} \cap R_{g h}$ and hence $a_{g} \in I_{g}$ or $b_{h} \in I_{h}$, since $I$ is an n-almost graded prime ideal in $\mathrm{R}$. Thus $\mathrm{a}_{\mathrm{g}}+\mathrm{I}^{\mathrm{n}} \in\left(\mathrm{I} / \mathrm{I}^{\mathrm{n}}\right)_{\mathrm{g}}$ or $\mathrm{b}_{\mathrm{h}}+\mathrm{I}^{\mathrm{n}} \in\left(\mathrm{I} / \mathrm{I}^{\mathrm{n}}\right)_{\mathrm{h}}$ which implies that $\mathrm{I} / \mathrm{I}^{\mathrm{n}}$ is weakly graded prime ideal in $\mathrm{R} / \mathrm{I}^{\mathrm{n}}$.

Conversely, suppose that $\mathrm{I} / \mathrm{I}^{\mathrm{n}}$ is weakly graded prime ideal in $\mathrm{R} / \mathrm{I}^{\mathrm{n}}$ and let:

$$
a_{g} b_{h} \in I_{g h}-\left[I^{n} \cap R_{g h}\right]
$$

Then:

$$
\left(a_{g}+I^{n}\right)\left(b_{h}+I^{n}\right)=a_{g} b_{h}+I^{n} \neq 0 \in\left(I / I^{n}\right)_{g h}
$$

Since $I / I^{\mathrm{n}}$ is weakly graded prime ideal in $\mathrm{R} / \mathrm{I}^{\mathrm{n}}$ then $\mathrm{a}_{\mathrm{g}}+\mathrm{I}^{\mathrm{n}} \in\left(\mathrm{I} / \mathrm{I}^{\mathrm{n}}\right)_{\mathrm{g}}$ or $\mathrm{b}_{\mathrm{h}}+\mathrm{I}^{\mathrm{n}} \in\left(\mathrm{I} / \mathrm{I}^{\mathrm{n}}\right)_{\mathrm{h}}$ which implies that $a_{g} \in I_{g}$ or $b_{h} \in I_{h}$, thus $I$ is an n-almost graded prime ideal in $\mathrm{R}$.

\section{CONCLUSION}

The developing theory of almost and n-almost prime ideals were extended smoothly to the graded case, and the extension of some basic results (Theorem 2 and Theorem 3) would help us to classify further properties about almost and n-almost graded prime ideals.

\section{REFERENCES}

1. Anderson, D. and E. Smith, 2003. Weakly prime ideals. Houston J. Math., 29: 831-840. http://www.math.uh.edu/ hjm/Vol29-4.html.

2. Anderson, D. and S. Leon, 1996. Factorizations in commutative rings with zero divisors. Rocky Mountain J. Math., 26: 439-480. DOI: 10.1216/RMJM/1181072068.

3. Atani, S.E., 2006. On graded weakly prime ideals. Turk. J. Math., 30: 351-358. http://www.m-hikari. com/imf-password/1-4-2006/ebrahimiataniIMF1-42006.pdf.

4. Bhatwadekar, M. and P. Sharma, 2005. Unique factorization and birth of almost primes. Commun. Algebra, 33: 43-49. DOI: 10.1081/AGB200034161.

5. Refai, M. and K. AL-zoubi, 2004. On Graded Primary Ideals. Turk. J. Math., 28: 217-229. http://journals.tubitak.gov.tr/math/issues/mat-0428-3/mat-28-3-2-0301-6.pdf. 